\title{
A CASE WITH A TERMINAL DELETION OF THE LONG ARM OF CHROMOSOME 7
}

\author{
Yoshifumi Kodama, ${ }^{1}$ Kouji Narahara, ${ }^{1}$ Hiroshi Yabuuchi, ${ }^{1}$ \\ Akiko Hirano, ${ }^{2}$ Hideo Inoue, ${ }^{2}$ Shunsuke Kimura, ${ }^{1}$ \\ and Hiroshi Kimoto ${ }^{1}$ \\ ${ }^{1}$ Department of Pediatrics, Okayama University School of Medicine, \\ Okayama 700, Japan \\ ${ }^{2}$ Department of Pediatrics, Okayama Saiseikai Sougou Hospital, \\ Okayama 700, Japan
}

\begin{abstract}
Summary A malformed female infant with a de novo $7 \mathrm{q}$ terminal deletion (q32 $\rightarrow$ qter) resulting from interchange between chromosome 4 and 7 was described. Her phenotype had a close resemblance to those of the previously reported cases. A further delineation of clinical features of $7 \mathrm{q}$ terminal deletion syndrome was attempted.
\end{abstract}

\section{INTRODUCTION}

Up to date, 25 cases with partial monosomy $7 \mathrm{q}$ have been reported, and 10 out of those cases showed a terminal deletion $7 \mathrm{q} 32 \rightarrow 7 \mathrm{qter}$. The clinical entity associated with this deletion has firstly been suggested by Harris et al. (1977). The clinical pictures of this syndrome, however, still await further elucidation.

\section{CASE REPORT}

The patient was born after 41 weeks of normal gestation. She was the first child of a 26-year-old mother and a 28 -year-old father. The parents were unrelated. Family history was not contributory. The delivery was induced because of weak pains, and the Apgar Scores were 5 at 1 minute. At birth, she weighed $1,880 \mathrm{~g}$ and measured $41.2 \mathrm{~cm}$, with her head circumference $29.5 \mathrm{~cm}$. The following abnormalities were noted: microcephaly, bushy eyebrows, hypertelorism, exophthalmus, divergent strabismus, blue sclera, short nose with broad nasal tip and anteverted nostrils, long and prominent philtrum, thin upper lip, low-set ears with simple and round auricles, micrognathia, irregular alveolar ridge, systolic heart murmurs, sacral dimple, long slender trunk, small pelvis and cutis marmorata (Fig. 1). Dermatoglyphic patterns on fingertips, palms and soles were obscure due to ridge hypoplasia, but palmar flexion creases were found to be deep. 
Laboratory investigations including complete blood count, urinalysis, serum electrolytes, serum thyroid hormone values and urinary aminogram showed all within normal ranges. X-ray examination revealed that the skeletal system was normal, and computerized cranial tomography scan revealed slight enlargement of
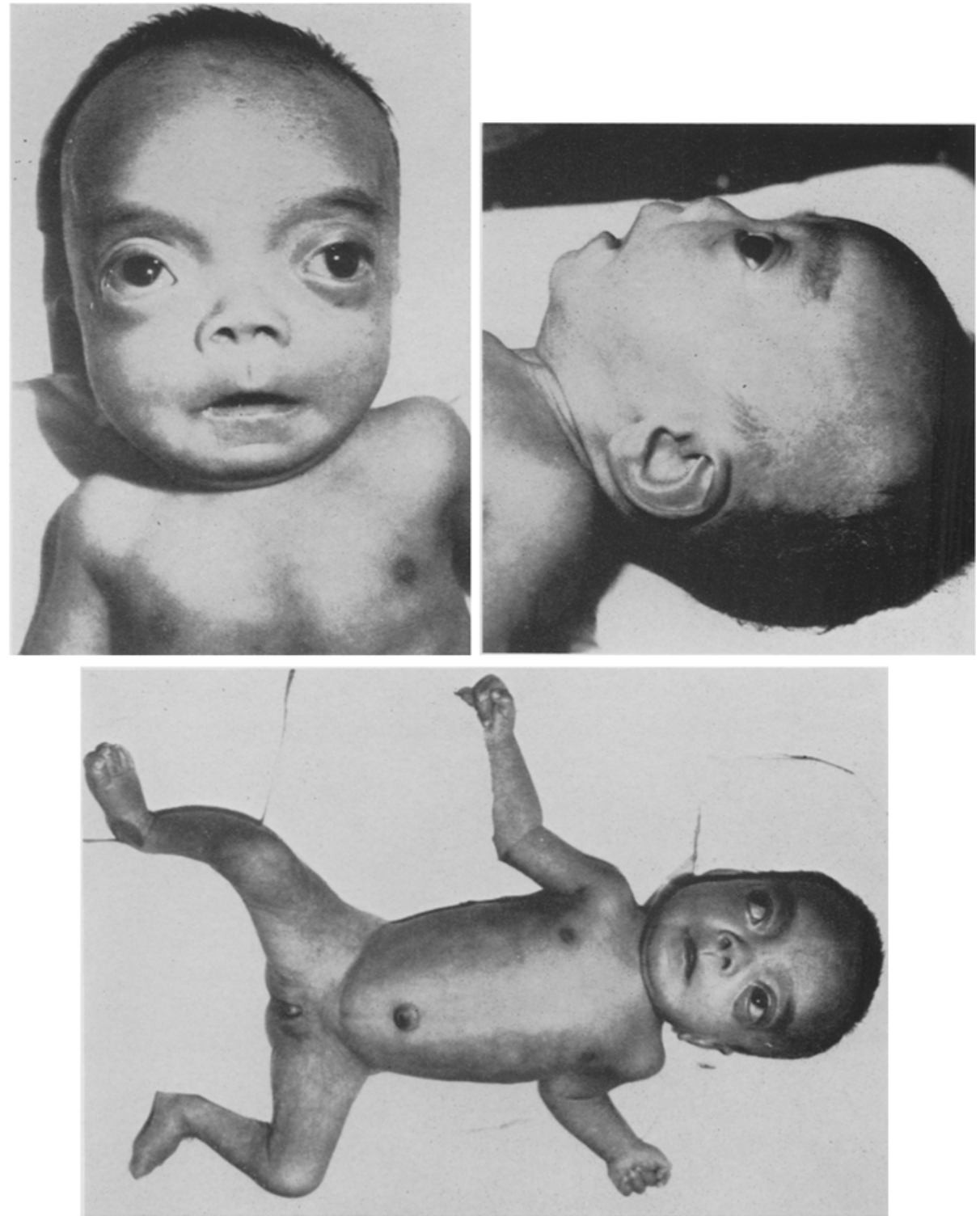

Fig. 1. Appearance of the patient. Note bushy eyebrows, hypertelorism, exophthalmus, divergent strabismus, short nose with broad nasal tip and anteverted nostrils, long and prominent philtrum, and ear malformation. 
the lateral ventricles. There was no serologic evidence for intrauterine infections (congenital toxoplasmosis, rubella, or cytomegalic inclusion disease).

Feeding difficulty and cyanosis on crying had been present since birth, and she had been failing to thrive. At 5 months of age, she weighed only $2,070 \mathrm{~g}$. Her psychomotor development was also severely retarded. She died of congestive heart failure at 5 months. Autopsy disclosed ventricular septal defect and patent ductus arteriosus.

\section{CYTOGENETIC FINDINGS}

Cytogenetic studies were performed on cultured peripheral blood lymphccytes from the patient and her parents. Chromosome analyses using GTG, QFQ, and RHG-bandings revealed that the patient had a chromosome count of 46 . A complicated rearrangement involving chromosomes 4 and 7 was present in all of the cells studied (Fig. 2). Based on the examination of the G-banding patterns of

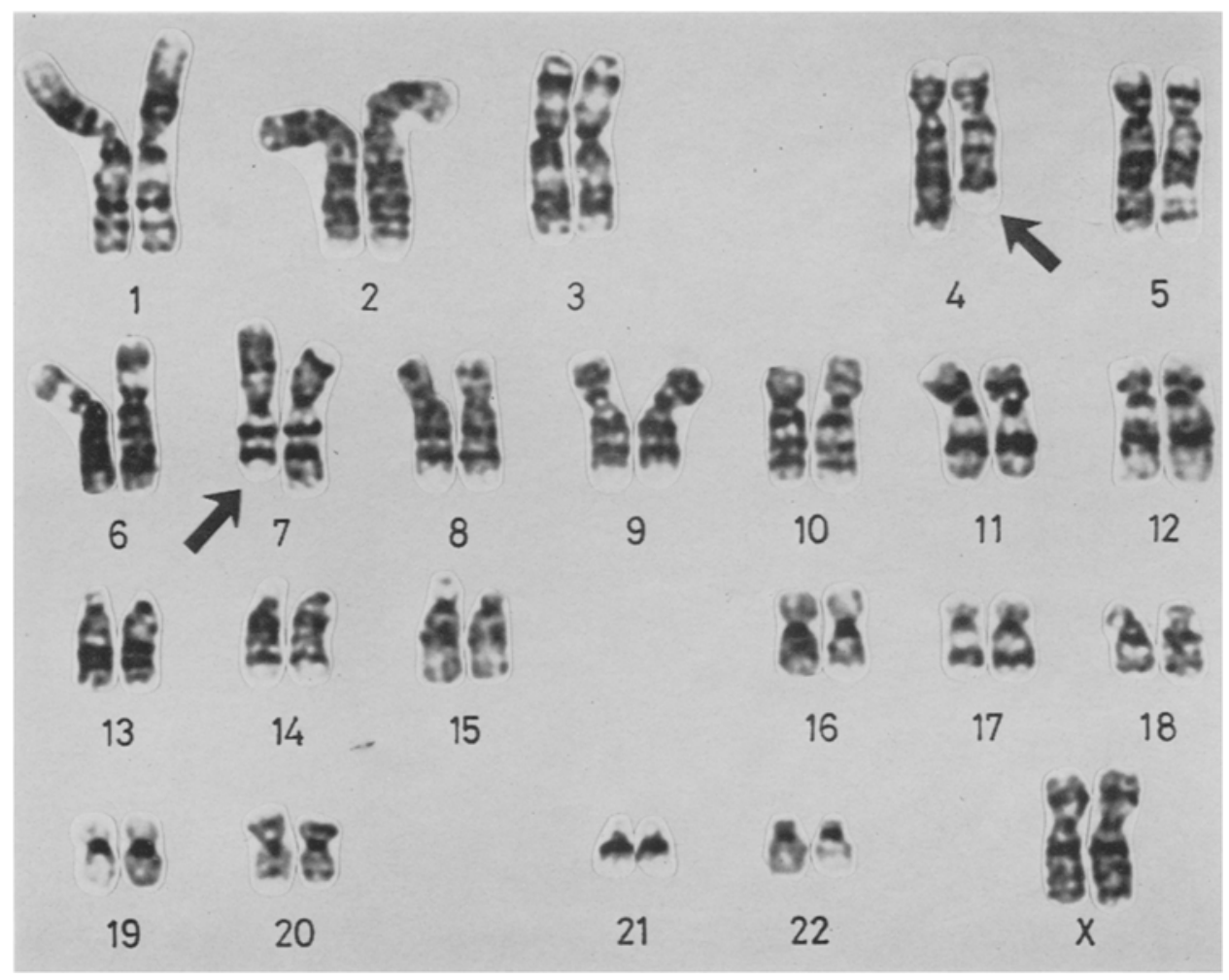

Fig. 2. Complete G-banded karyotype of the patient. Arrows indicate rearranged chromosomes 4 and 7. 
chromosomes from early metaphases (Fig. 3a), the most pertinent interpretation of this rearrangement was as follows: the segment $\mathrm{q} 311 \rightarrow$ qter of a chromosome 4 was transposed to $\mathrm{p} 22$ of a chromosome 7 , and the segment $\mathrm{p} 22 \rightarrow \mathrm{pter}$ of the chromosome 7 rejoined with the broken end of the chromosome 4 (4q311), while the segment $\mathrm{q} 32 \rightarrow \mathrm{qter}$ of the chromosome 7 was deleted. Although there could be another interpretation that the segment $7 \mathrm{p} 22 \rightarrow$ pter reunited with $7 \mathrm{q} 32$ instead

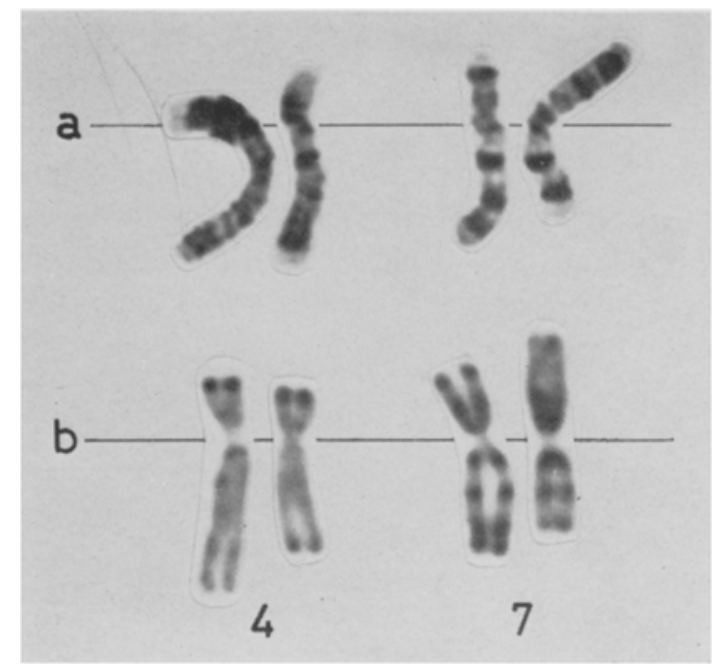

Fig. 3. Partial karyotype of the patient. a, G-banding; b, Rbanding.

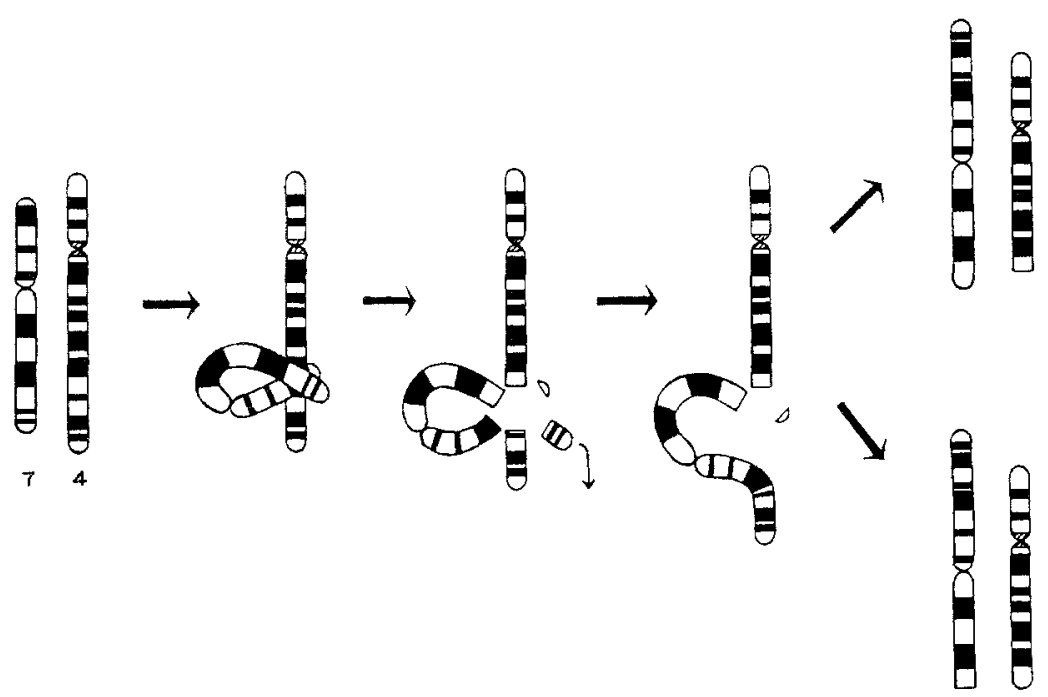

Fig. 4. Schematic representation of the process through which a three-break-event have produced $7 \mathrm{q}$ terminal deletion. 
of 4q311, R-banding analysis was more consistent with our interpretation (Fig. 3b). Consequently, the patient was thought to be monosomic for the segment $7 \mathrm{q} 32 \rightarrow$ qter.

Three breakpoints $(4 \mathrm{q} 311,7 \mathrm{p} 22$, and $7 \mathrm{q} 32)$ were identified in this arrangement. It appeared that the abnormal karyotype in the patient would be the result of a three-break-event involving the two chromosomes. The process, through which the three-break-event would have produced the terminal $7 \mathrm{q}$ deletion, could be speculated as shown in Fig. 4.

\section{DISCUSSION}

The previously reported cases with partial monosomy $7 \mathrm{q}$ can be classified into five groups based on cytogenetic findings: (1) An interstitial deletion 7q11 $\rightarrow 7 \mathrm{q} 21$ or q22 in 6 cases (Valentine and Sergovich, 1977; Seabright and Lewis, 1978; Klepde Pater et al., 1979; Crawfurd et al., 1979), (2) An interstitial deletion 7q21 $\rightarrow 7 \mathrm{q} 31$ or q32 in 4 cases (Ayraud et al., 1976; Higginson et al., 1976; Franceschini et al., 1978; Klep-de Pater et al., 1979), (3) A terminal deletion 7q32 $\rightarrow 7$ qter in 10 cases (de Grouchy et al., 1968, 1974; Shokeir et al., 1973; Harris et al., 1977; Kousseff et al., 1977; Biederman and Bowen, 1978; Bernstein et al., 1980), (4) An interstitial deletion $7 \mathrm{q} 32 \rightarrow 7 \mathrm{q} 34$ in 3 related cases (Nielsen et al., 1979) (The possibility that the interstitial deletion involved the segment $7 \mathrm{q} 32 \rightarrow \mathrm{q} 36$ was also suggested by the authors.), and (5) A terminal deletion 7q35 $\rightarrow 7 \mathrm{qter}$ in 2 cases (Francke, 1978; Turleau et al., 1979). As for the groups 1 and 2, there are still few consistent features. On the other hand, the group 3 appears to constitute a clinically recognizable syndrome, as has been suggested by Harris et al. (1977).

In order to make a further delineation of the phenotypic features of the terminal deletion $7 \mathrm{q} 32 \rightarrow 7 \mathrm{qter}$ syndrome, clinical findings of the cases in the groups 3,4 and 5 were summarized in Table 1. The phenotype of the present case had a close resemblance to those of the group 3 cases. Characteristic craniofacial dysmorphia for terminal deletion $7 \mathrm{q} 32 \rightarrow 7 \mathrm{qter}$ consisted of microcephaly, hypertelorism, broad nasal tip, short nose, anteverted nostrils, long and prominent philtrum, and ear malformations. Frontal bossing, though less frequently found, seemed to be an important feature as well. The present case, in addition, exhibited exophthalmus and thin upper lip, which were also described in three other cases, respectively. Further case studies may be desirable before determining whether these symptoms represent additional features characteristic for $7 \mathrm{q}$ terminal deletion. Mental retardation and growth failure were always present. In male cases, genital abnormalities were also usual findings. Low birth weight was noticed in two thirds of the cases. Congenital heart disease was observed only in the present case. This malformation apparently had an unfavorable influence upon her life. All other cases were reported to be alive, and the absence of serious internal malformations was probably the reason for their good life prognosis. 
Table 1. Clinical findings of the cases with distal $7 q$ deletions.

\begin{tabular}{|c|c|c|c|c|}
\hline & $\begin{array}{l}\text { Present } \\
\text { case }\end{array}$ & $\begin{array}{c}\text { Group } 3 \\
\text { del(7) } \\
\text { (q32 } \rightarrow \text { qter) }\end{array}$ & $\begin{array}{c}\text { Group } 4 \\
\text { del( } 7) \\
(\mathrm{q} 32 \rightarrow \mathrm{q} 34 \text { or } q 36)\end{array}$ & $\begin{array}{c}\text { Group } 5 \\
\text { del(7) } \\
\text { (q35 } 35 \rightarrow \text { qter) }\end{array}$ \\
\hline Low birth weight & + & $6 / 9$ & $0 / 3$ & $2 / 2$ \\
\hline Growth failure & + & $9 / 9$ & $1 / 3$ & $2 / 2$ \\
\hline Mental retardation & + & $9 / 9$ & $3 / 3$ & $1 / 1$ \\
\hline Microcephaly & + & $9 / 9$ & $0 / 3$ & $2 / 2$ \\
\hline Broad nasal tip & + & $9 / 10$ & $3 / 3$ & $2 / 2$ \\
\hline Low-set and/or malformed ears & + & $8 / 9$ & $2 / 3$ & $2 / 2$ \\
\hline Anteverted nostrils & + & $8 / 9$ & $0 / 0$ & $2 / 2$ \\
\hline Short nose & + & $6 / 7$ & $3 / 3$ & $2 / 2$ \\
\hline Abnormal genitalia in males & 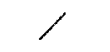 & $5 / 5$ & $0 / 1$ & $0 / 1$ \\
\hline Long and prominent philtrum & + & $4 / 5$ & $0 / 0$ & $2 / 2$ \\
\hline Hypertelorism & + & $5 / 7$ & $3 / 3$ & $0 / 1$ \\
\hline Frontal bossing & - & $5 / 10$ & $0 / 3$ & $2 / 2$ \\
\hline Simian lines & - & $5 / 8$ & $0 / 3$ & $0 / 1$ \\
\hline Hypotonia & + & $4 / 8$ & $0 / 3$ & $0 / 2$ \\
\hline Exophthalmus & + & $3 / 6$ & $0 / 3$ & $0 / 2$ \\
\hline Thin upper lip & + & $3 / 5$ & $0 / 3$ & $1 / 1$ \\
\hline Micro- and/or retrognathia & + & $3 / 6$ & $1 / 3$ & $2 / 2$ \\
\hline Inguinal hernia & - & $3 / 10$ & $0 / 3$ & $0 / 2$ \\
\hline Cleft palate and/or lip & - & $3 / 10$ & $0 / 3$ & $0 / 2$ \\
\hline Congenital heart disease & + & $0 / 10$ & $0 / 3$ & $0 / 2$ \\
\hline
\end{tabular}

As shown in Table 1, the groups 4 and 5 had many features in common with the group 3. The comparison of phenotypes between the three groups permitted us to suppose that most of the basic features of this syndrome could be associated with monosomy for the segment $7 \mathrm{q} 35 \rightarrow 7 \mathrm{qter}$. The failure to establish more precise correlations between each feature and specific segments may be ascribed in large part to the equivocal location of the distal breakpoint of the group 4. Except for certain features, however, the phenotype of the group 4 was similar to that of the group 5. This would suggest that the monosomic segments of these two groups may be indeed overlapping and the distal breakpoint of the group 4 was more likely to be at $7 \mathrm{q} 36$.

Finally, it should be noted that $7 \mathrm{q} 32$ was the most frequent breakpoint involved in cases with partial monosomy $7 \mathrm{q}$, and terminal deletions $7 \mathrm{q} 32 \rightarrow 7 \mathrm{qter}$ had arisen de novo in all cases but one (Case 1 of Bernstein et al., 1980). This would lead us to assume that $7 \mathrm{q} 32$ may be a region very liable to break. 


\section{REFERENCES}

Ayraud, N., Rovinski, J., Lambert, J.C., and Galiana, A. 1976. Délétion interstitielle du bras long d'un chromosome $7 \mathrm{chez}$ une enfant lepréchaune. Ann. Génét, 19: 265-268.

Bernstein, R., Dawson, B., Morcom, G., Wagner, J., and Jenkins, T. 1980. Two unrelated children with distal long arm deletion of chromosome 7 : clinical features, cytogenetic and gene marker studies. Clin. Genet. 17: 228-237.

Biederman, B., and Bowen, P. 1978. Balanced $t(8 ; 9)(q 12 ; q 33)$ pat carrier with phenotypic abnormalities attributable to a de novo terminal deletion of the long arm of chromosome 7 . Human Genet. 41 : 101-107.

Crawfurd, M. d'A., Kessel, I., Liberman, M., McKeown, J.A., Mandalia, P.Y., and Ridler, M.A.C. 1979. Partial monosomy 7 with interstitial deletions in two infants with differing congenital abnormalities. I. Med. Genet. 16: 453-460.

Franceschini, P., Silengo, M.C., Davi, G.F., Santoro, M.A., Prandi, G., and Fabris, C. 1978. Interstitial deletion of the long arm of chromosome $7: 46, X X, \operatorname{del}(7)(p t e r \rightarrow q 2200:: q 3200 \rightarrow$ qter). Human Genet. 44: 345-348.

Francke, U. 1978. Hageman (factor XII) locus on 7q? Human Genet. 45: 363-367.

Grouchy, J. de, Veslot, J., Bonnette, J., and Roidot, M. 1968. A case of ?6p- chromosomal aberration. Am. J. Dis. Child. 115: 93-99.

Grouchy, J. de, and Turleau, C. 1974. Tentative localization of a Hageman (factor XII) locus on 7q, probably the 7q35 band. Humangenetik 24: 197-200.

Harris, E.L., Wappner, R.S., Palmer, C.G., Hall, B., Dinno, N., Seashore, M.R., and Breg, W.R. 1977. 7q deletion syndrome (7q32 $\rightarrow$ 7qter $)$ Clin. Genet. 12: 233-238.

Higginson, G., Weaver, D.D., Magenis, R.E., Prescott, G.H., Haag, C., and Hepburn, D.J. 1976. Interstitial deletion of the long arm of chromosome No. 7 (7q-) in an infant with multiple anomalies. Clin. Genet. 10: 307-312.

Klep-de Pater, J.M., Bijlsma, J.B., Bleeker-Wagemakers, E.M., France, H.F. de, and Vries-Ekkers, C.M.A.M. de. 1979. Two cases with different deletions of the long arm of chromosome 7. J. Med. Genet. 16: 151-154.

Kousseff, B.G., Hsu, L.Y.F., Paciuc, S., and Hirschhorn, K. 1977. A partial long arm deletion of chromosome 7: 46,XY, del(7)(q32). J. Med. Genet. 14: 144-147.

Nielsen, K.B., Egede, F., Mouridsen, I., and Mohr, J. 1979. Familial partial 7q monosomy resulting from segregation of an insertional chromosome rearrangement. J. Med. Genet. 16: 461-466.

Seabright, M., and Lewis, G.M. 1978. Interstitial deletion of chromosome 7 detected in three unrelated patients. Human Genet. 42: 223-226.

Shokeir, M.H.K., Ying, K.L., and Pabello, P. 1973. Deletion of the long arm of chromosome No. 7: tentative assignment of the Kidd (Jk) locus. Clin. Genet. 4: 360-368.

Turleau, C., Grouchy, J. de, Perignon, F., and Lenoir, G. 1979. Monosomie 7qter. Ann. Génét. 22: 242-244.

Valentine, H., and Sergovich, F. 1977. A syndrome associated with interstitial deletion of chromosome 7q. Birth Defects Original Article Series 13: 261. 